\title{
Genetic influences on tone? New experimental evidence and its consequences for linguistics.
}

\author{
Dan Dediu ${ }^{1}$ and D. Robert Ladd ${ }^{2}$
}

\author{
${ }^{1}$ Laboratoire Dynamique Du Langage UMR 5596, Université Lumière Lyon 2, Lyon, France \\ 2 Linguistics and English Language, The University of Edinburgh, Edinburgh, UK \\ ${ }^{*}$ Corresponding author: dan.dediu@univ-lyon2.fr
}

\begin{abstract}
In 2007, we used a cross-linguistic statistical analysis to show that there seems to be a negative correlation between the population frequency of the "derived" alleles of two genes involved in brain growth and development, ASPM and Microcephalin (or MCHP1), and the use of tone in the language(s) spoken by the population. Despite our best attempts at disentangling the confounding effects of contact and genealogical inheritance, and the fact that these correlations stood out among millions of similar correlations between multiple genetic markers and linguistic features, this was, at best, a statistical association and, at worst, a false positive. However, new experimental evidence has recently been published independently of us, showing that the negative correlation between the "derived" allele of $A S P M$ and tone perception and/or processing is present at the level of inter-individual differences among more than 400 native speakers of Cantonese, providing strong support for our initial findings (on the other hand, there is no signal for MCPH1). Here we contextualize and summarize these experimental findings, we address some remaining puzzles (including MCHP1 and the absence of tone in Australia), and we discuss the implications of these results for the language sciences.
\end{abstract}




\section{Introduction: genetic influences on language and speech}

At the most general level, it is beyond debate that there is something about the human genome that makes language possible. More and more evidence points to particular genes and pathways that affect various aspects of speech and language production, perception, acquisition and processing (for good overviews see for example Fisher and Vernes 2015, Devanna, Dediu, and Vernes 2018, and Deriziotis and Fisher 2017). For the most part, these findings concern universally shared aspects of language and speech (e.g., building a brain capable of supporting language, Fisher 2019, Boeckx and Benítez-Burraco 2014, or a vocal tract able to produce fast, coordinated speech, Gokhman et al. 2020). However, some studies also consider inter-individual variation. Such research is often concerned with 'pathological' variation (e.g., having a cleft palate, which may be due to mutations in the FGFR2 gene and which profoundly affects speech production, Dixon et al. 2011, or Developmental verbal dyspraxia (DVD) due to the truncation of the FOXP2 gene, MacDermot et al. 2005). Yet it is easy to lose sight of the fact that there is also a wide range of what might be called 'normal' variation. While currently less studied than pathological variation, normal variation between individuals is ubiquitous and can be found at all levels (molecular, physiological, anatomical, psychological and neuro-cognitive). It ranges from tiny differences, barely detectable even with advanced laboratory techniques, through effects that may be seen as 'idiosyncrasies', to differences easily noticeable with the naked eye (or ear).

Our concern here is not with either pathological or idiosyncratic 'normal' variation, but with the possibility that normal variation between individuals might be structured between groups in such a way as to influence the languages of the groups - the wider linguistic communities - to which individuals belong. Put more simply, could there be genetic variation that somehow affects the languages spoken by groups that differ genetically in some way? This question may usefully be decomposed into two components. First, is inter-individual variation structured 
between groups? And if so, then second, how could such inter-individual variation affect whole languages?

With regard to the first question, the last decades have produced overwhelming evidence that, due to our evolutionary and demographic history, most of the interindividual genetic variation is geographically structured in complex ways (Jobling et al. 2013, Barbujani and Colonna 2010, Reich 2018). We know, for example, that due to the major role played by Africa in our evolution, variation is greatest there, and decreases in a continuous, gradual manner with the distance from Africa. We also know that, comparatively speaking, we are fairly homogeneous genetically: our species - now spread across the whole world and approaching 8 billion individuals is less genetically diverse than the chimpanzees (Bowden et al. 2012). Moreover, the bulk of what variation we find is distributed not between continents $(\sim 8 \%)$, nor between groups (another $\sim 8 \%$ ), but between individuals within a group (Lewontin 1972, Barbujani and Colonna 2010). Nevertheless, some genetic variants retain very strong signals of past demography: single genetic markers rarely if ever carry enough information (Jobling et al. 2013, Reich 2018), but in some cases combining the signals from several such markers allows the precise tracing of individual ancestry to quite specific geographic and cultural groups (Nassir et al. 2009, Paschou et al. 2010). It is therefore certainly possible that there may exist normal inter-individual genetic variation that affects speech and language and that is structured between groups.

As for the second question, there have been suggestions about how group differences might affect language (Ladd, Dediu, and Kinsella 2008). For example, Ladefoged (1984) showed that the vowels of Italian and Yoruba, which in broad IPA terms have 'identical' seven-vowel systems, show subtle acoustic differences that are consistent with the differences in facial structure between the typical speakers of the two languages. He was careful to point out that this difference did not mean that an Italian could not learn phonetically perfect Yoruba, or vice-versa, but he implied that the anatomical differences could provide some sort of bias that would yield subtle effects on the languages spoken by the two groups. But these ideas are certainly much older: 
Brosnahan (1961), building on an even earlier suggestion by Darlington (1947), proposed that such biases rooted in genetics might influence language structure through their effects on intergeneration transmission. The details of Brosnahan's proposal have not aged well, but the general idea is strikingly in line with more recent proposals. Evidence from computational and mathematical models (Dediu 2008, Dediu 2009, Thompson, Kirby, and Smith 2016, Kirby, Dowman, and Griffiths 2007, Smith 2009; Perfors and Navarro 2011, Navarro et al. 2018, Josserand et al. in preparation) and from lab experiments (Kirby, Cornish, and Smith 2008, Smith and Wonnacott 2010, Raviv 2020), does suggest that, under certain conditions, small inter-individual variation can be amplified by the repeated use and transmission of language. Note the two claims being made here: on the one hand, there are interindividual differences that need not have any obvious effect on an individual's language, but on the other hand, if such differences are structured between groups, they may exert an influence on the way a language changes during repeated use and transmission.

\section{Linguistic tone and genes: a cross-linguistic statistical correlation}

In 2007, we published a paper (Dediu and Ladd 2007) that hypothesized the existence of a specific case of this kind of influence, namely a possible genetic basis for the very uneven geographic distribution of tone languages in the world. (As is well known, tone languages are concentrated in Southeast Asia, sub-Saharan Africa, and a few parts of the Americas). Everything started with the publication in September 2005 of two papers in Science on genetic variation in two genes (ASPM and MCHP1 (or Microcephalin)) apparently involved in brain growth and development (Evans et al. 2005, and Mekel-Bobrov et al. 2005; for more detail see the Appendix). These papers showed that both genes have newer 'derived' alleles (variants) alongside their older original alleles, and that the two alleles of both genes are very unevenly distributed geographically: at first glance, the map of the older and newer allele frequencies in the two Science papers looks remarkably similar to a map of the distribution of languages with and without tone (Ladd, Dediu, and Kinsella 2008). This informal 
observation meshed very well with the view articulated by Dediu (2007) that, because language and speech have a genetic foundation, there should be aspects of cross-linguistic diversity that are due to inter-group genetic variation.

We therefore hypothesized that there is more to this visual match than meets the eye. Specifically, we proposed that:

1. there is a causal effect of the alleles of these two genes (which the original papers referred to as ' $\mathrm{D}$ ' and 'non- $\mathrm{D}$ ', for the 'derived' and 'ancestral' forms, respectively) on an individual's learning, perception, production or processing of pitch, such that

2. the ' $D$ ' alleles generate some kind of negative bias against the type of linguistic use of pitch found in tone languages (but not against intonation, music and other uses), and that

3. the bias is very tiny at the individual level (since, obviously, any normal child and most normal adults can perfectly acquire even extremely complex tone systems), but

4. is amplified, in populations with a high frequency of similarly biased individuals, to the level at which it can 'nudge' the whole language away from using linguistic tone, by either promoting tone loss or by blocking tonogenesis. We detailed our view of the intergenerational transmission and amplification in a subsequent paper (Ladd, Dediu, and Kinsella 2008).

Causal explanations for correlations are notoriously hard to test (Ladd, Dediu, and Kinsella 2008, Ladd, Roberts, and Dediu 2015, Dediu 2011), and all we could do in the 2007 paper was to conduct a cross-linguistic correlational study. The goal of that study was to see if there is a rigorous statistical basis for the visual impression based on the maps of the distribution of tonal and non-tonal languages and the distribution of the 'D' and 'non-D' alleles of the two genes. Specifically, we looked for a correlation between the frequency of the ' $\mathrm{D}$ ' alleles in a given population and whether the language(s) spoken by that population are classified as tonal; we also extensively explored whether any such association can be explained away by various confounds 
such as the historical relatedness and the geographical distance between languages. Since we had no independent information about the population frequency of the ' $D$ ' alleles, we tested the hypothesis on the basis of the populations reported in Evans et al. (2005) and Mekel-Bobrov et al. (2005). For the languages spoken by these populations, we coded 27 typological linguistic variables (26 diverse structural features of the language in addition to whether they were tonal or non-tonal), and collected frequency data for 983 genetic markers spread across the genome in addition to the frequency of the ' $\mathrm{D}$ ' alleles reported in the original Science papers. We found that the correlation between the two genes and tone, after controlling for geographical and genealogical distance, is significant and stronger than the vast majority of the other possible correlations between genetic and linguistic variables (see Dediu and Ladd 2007 and Dediu 2007 for details, or the Appendix for a brief summary). We took this as suggesting that there is some connection between tone, $A S P M$-D, and MCPH1-D that is not due to shared ancestry and contact, and this is the finding we published.

However, even ignoring the skepticism that many mainstream linguists show for language-external explanations of this kind, our study could be seen as, at best, a demonstration of a statistical association between linguistic and genetic diversity that would be worth following up. We pointed this out in the paper itself (Dediu and Ladd 2007:10947) and in our own commentaries at the time (Dediu 2007, Ladd, Dediu, and Kinsella 2008, Dediu 2011). We knew that, while bigger and better population-level cross-linguistic studies might add evidence, the strongest type of follow-up test would involve individual-level genetics and psycholinguistics. Yet it was, and to a considerable extent still is, far from obvious how to proceed. For one thing, we were handicapped by having no realistic prospect of doing genetic studies, but even on the psycholinguistic side there were many possible avenues to explore, and many ideas about the kinds of pathways that an influence from genes to tone languages might take. Following the publication of the 2007 correlation study, we investigated the perception of missing fundamental tones (Ladd et al. 2013), the segmentation of streams of syllables exhibiting variation in pitch (Caldwell-Harris et 
al. 2015), and the learning of artificial tone languages in an fMRI paradigm (Asaridou et al. 2016). At best, these studies resulted in interesting but hardly decisive results relevant to the original hypothesis. During the same period, however, Patrick Wong and his collaborators took a radically different approach, which led to the discovery to which we devote the rest of this report.

\section{Experimental evidence that ASPM-D affects tone in individuals}

Wong's fundamental insight was to keep the linguistic and 'ethnic' background of their participants constant, and to focus on detecting the association between an individual's genotype (with respect to the ' $\mathrm{D}$ ' alleles of ASPM and MCHP1) and the same individual's performance on a set of tasks arguably related to linguistic tone. Their first study (Wong, Chandrasekaran, and Zheng 2012) was based on 32 young adult native speakers of American English, all self-identified 'Caucasians', who were genotyped to ascertain their 'load' of the ' $\mathrm{D}$ ' alleles of ASPM and MCPH1. Because everyone inherits two copies of most genes, one from each parent, everyone has zero, one, or two copies of the ' $\mathrm{D}$ ' variant of these two genes; for the analysis of the results, the experimental participants were classified into one of these three categories for each of the genes under investigation. The experiments involved a variety of cognitive tasks, crucially including labeling the pitch direction on resynthesized vowels with rising, level, or falling pitch. In a smaller (13 participants) follow-up study, participants listened to sequences of such resynthesized stimuli while their brain responses were monitored using fMRI, to assess sensitivity to pitch differences between adjacent stimuli. More detail on these experiments is given in the Appendix.

The results were striking, but also worrying. First, contrary to what was suggested by Dediu and Ladd (2007), MCPH1 was not associated with anything in the participants' behavior. Second and more importantly, the ASPM load was - as predicted significantly correlated with score on the pitch direction task and with a particular response pattern on the fMRI study, but the relationship seemed to be in the wrong direction. Participants with more ASPM-D alleles were better at perceiving the pitch 
direction on the synthesized vowels, and their brain activity showed more of a specific response type ('repetition suppression') that might be expected to indicate sensitivity to pitch. Thus, taken at face value, this study does indeed suggest that the 'D' allele of ASPM (though not of MCPH1) has something to do with the processing of pitch (both at the behavioral and neural levels), but in the opposite way to what was proposed in the Dediu and Ladd study that generated the tested hypothesis in the first place.

What could this mean? First, the study is very small, and its results concerning ASPM could simply be false positives (Type I error). Second, if the results are not statistical artifacts, they do offer partial support to the original hypothesis in Dediu and Ladd (2007), in the sense that $A S P M$ is involved in some way with the perception of pitch in speech. The fact that the relationship is the opposite of the expected one might be due, as Wong, Chandrasekaran, and Zheng (2012) themselves argue, to differences in methodology, to gene-gene and gene-culture interactions, and to the fact that the experimental study looked at speakers of a non-tone language (English) reacting to tone language (Mandarin Chinese) stimuli. Another possibility, developed in Caldwell-Harris et al. (2015:340), is that Wong et al.'s tone perception task does not capture what native speakers of tone languages do, but rather more closely resembles what speakers of intonation languages do, namely to separate pitch from the segmental content and process it separately. If this is so, then these results are actually in the direction predicted in Dediu and Ladd (2007)! In either case, we are still far from having the results of a crucial experiment to confirm or reject Dediu and Ladd's suggestion.

Wong eventually obtained funding for a much larger study that aimed to address some of these puzzles. In May 2020, he and his colleagues published a new paper (Wong et al. 2020) reporting a very large study in which they tested more genes and more phenotypes, and used a more refined test battery. As in the 2012 study, they kept the linguistic and 'ethnic' backgrounds constant, but this time they focused on young adult native speakers of a language with a complex tone system, Cantonese; 
there were 426 participants in total, most from Hong Kong. Besides being genotyped for the 'D' alleles of ASPM and MCPH1, the participants were also genotyped at 20 other locations (loci) in their genome, in a total of 10 genes thought to be involved in brain/cranial volume/cortical area (MCPH1 - at a different locus - and CDK5RAP2), hippocampus volume (COMT), executive function (DRD1), working memory (DRD2), and various aspects of speech and language (CNTNAP2, ATP2C2, CMIP and FOXP2). The participants passed a hearing test, reported the number of years of musical training, and performed a test of non-verbal intelligence and four experimental tasks. These were:

- 'lexical tone perception' (an 'ABX' task based on well-formed but meaningless Cantonese syllables (pseudowords), where the participant judged whether the tone on the last syllable $(\mathrm{X})$ in a series of three syllables was the same as the tone on the first (A) or the second (B); for a given stimulus series, the three syllables differed only in tone);

- 'musical pitch perception' (in which the participant judged whether pairs of short melodies that might differ in a single note were identical or not);

- 'rhythm perception' (similar to the musical pitch perception task, but where the melodies might differ in rhythm); and

- 'running working memory' (in which the participants had to reproduce on a computer keyboard a sequence of letters presented auditorily).

Again, the results were striking. It is presumably no surprise that there is interindividual variation in non-verbal IQ, working memory, years of musical training, and ability to handle musical pitch and rhythm, but the remarkable finding we highlight here is the amount of variation among these apparently normal young adults concerning a crucial aspect of their native language: lexical tone. The scores on the 'lexical tone perception' task vary between as low as 51\% (the chance level is 50\%) and $100 \%$. While many of the participants are well above $90 \%$ (the average is $87 \%$ ), a substantial number of participants performed below 75\% (see Wong et al. 2020, Table 1 and Figure S1). The authors used a variety of statistical techniques and checks 
for multiple testing to investigate the association between the four tasks and the genotyped loci. Even after controlling for the positive significant effects of the covariates non-verbal IQ and years of musical training, the only significant association they found with the genetic variables was between the performance on the 'lexical tone perception' task and ASPM-D. This time, the effect of ASPM-D was in the direction predicted by Dediu and Ladd (2007), with the derived allele 'D' negatively influencing the performance on the task relative to the 'non- $D$ ' allele; furthermore, the effect size seems to make sense, being comparable to other known cases. Neither $M C P H 1$ nor the other genes tested were associated with any of the four behavioral tasks used involving language and music, and ASPM was strictly associated with lexical tone perception only.

Independently of Wong's study, ASPM has been recently implicated in anatomical variation in the auditory cortex, including Heschl's gyrus (Passemard et al. 2016), which is involved in pitch processing. Taken together with Wong et al.'s results, these findings suggest that, in native Cantonese speakers, carrying the derived ' $D$ ' allele of the ASPM gene reduces the specific ability to correctly match Cantonese tone contours in an ABX task. The effect of this allele, while relatively large for such a simple mutation, is still small, certainly much smaller than the effects of the non-verbal IQ and musical training. This matches our original conception, in the sense that it involves an individually weak effect of the ' $D$ ' allele which can nevertheless easily be overridden by other factors, including the ambient language (Dediu and Ladd 2007, Ladd, Dediu, and Kinsella 2008).

\section{The good, the bad and the (potentially) ugly}

While Wong et al.'s study certainly lends plausibility to the speculation on which Dediu and Ladd 2007 was based, plenty of questions and potential objections remain. We briefly mention two of these here. 
First, what happened to MCPH1? While in our original work (Dediu and Ladd 2007, Dediu 2007) the statistical signals for both 'derived' alleles were similar, neither of Wong's studies (Wong, Chandrasekaran, and Zheng 2012, Wong et al. 2020) found any association for MCPH1-D. One possibility is that MCPH1-D does influence the cross-linguistic distribution of tone, but its individual effects were not captured by any of the experimental tasks used or are too weak to be detected (thus, an experimental false negative or type II error). The other possibility is that our original effect of MCPH1-D was a false positive. It is currently difficult to decide between these two possibilities, but we concede that the latter is probably more likely. In defense of our original correlation study, we note that any exploratory analysis is intrinsically likely to generate false positives; we should certainly take great care to minimize their probability, but we believe that we should not fall into the trap of throwing out the baby with the bathwater by being so aversive to false positives we miss genuine novelties. That is, we think that the costs of temporarily accepting MCPH1 into the select 'club' of genes that may affect language were negligible compared to not considering the influence of $A S P M$ on tone and to persevering in the belief that linguistic and biological diversities are separated by an unbreakable firewall.

Second, what about Australia? As we pointed out in our paper (Dediu and Ladd 2007:10947) Australia is particularly interesting for this hypothesis because its languages (irrespective of family) are eminently non-tonal and because, though actual genetic data were not available, one might expect that Aboriginal Australians should have very low frequencies of $A S P M$-D. This expectation was based on two considerations. First, the mutation that produced ASPM-D was dated at just about 6,000 years ago or so (Mekel-Bobrov et al. 2005:1722), while Australia seemed to have been relatively genetically isolated after the last glacial maximum about 8,000 years ago (Bergström 2018, Bergström et al. 2016, McEvoy et al. 2010; but see Pugach et al. 2013). Second, samples that were available for neighboring populations showed a very low frequency of $A S P M$-D. (For MCPH1-D the expectations are less clear.) Given this genetic inference, shouldn't at least some Australian languages be tonal? 
Far from being the single ugly fact that slays a beautiful hypothesis (to paraphrase T. H. Huxley), we think that non-tonal Australian languages highlight the crucial fact that our proposal is not deterministic, and that language change is simultaneously affected by many factors, very weak genetic biases being just one of them. In 2007 we were not yet aware of Butcher (2006)'s suggestion that several typologically rare properties of the Australian languages (such as the absence of fricatives, voicing contrasts, rich place of articulation distinctions) might be explained as the adaptation of these languages to the very high incidence of Chronic Otitis Media (COM) among Aboriginal Australian children. COM is a middle ear infection that can result in longterm partial hearing loss affecting the low (below about $500 \mathrm{~Hz}$ ) and high (above about $4000 \mathrm{~Hz}$ ) frequencies. Butcher's basic idea is fundamentally analogous to our own: COM changes the constraints and affordances of language change by generating a strong bias against conveying information in the affected frequencies (Levinson and Dediu 2013). The COM hypothesis is still far from being accepted (e.g., Round 2019), but we suggest that one of its predictions is that tone, like fricatives, should also be strongly disfavored in Australian languages, as the F0 range used to convey tone is well within the affected lower frequency band $(<500 \mathrm{~Hz})$ ! In other words, while the genetics of Australian Aborigines makes tone possible, the high incidence of ear infections would 'block' the 'exploration' of this possibility.

\section{Discussion and conclusions}

When we published our exploratory cross-population study in 2007, we imagined, rather optimistically, that experimental evidence, one way or the other, might be swift to follow, but it has taken 13 years. While far from being the last word on the possible link between ASPM and tone, we believe that Wong et al. (2020) is an important step forward, not least because it shows how different paradigms and scientific fields can fruitfully inform each other and produce research that is simply not possible within either one by itself. It also shows that 'risky' exploratory studies can lay the groundwork for careful experimental work that yields genuine discoveries. 
More specifically for the language sciences, we believe that the link between ASPM and tone - if confirmed by further psycholinguistic experiments, genetic association studies, and molecular genetic investigations - is simultaneously both marginal and fundamental. It is marginal because such influences, even if widespread, are small, specific, and in need of the whole gamut of cultural evolution in order to become apparent: they can be amplified and 'made visible', or they can be dampened and 'hidden' (Dediu and Ladd 2007, Dediu 2009, Thompson, Kirby, and Smith 2016, Kirby, Cornish, and Smith 2008). The overwhelming majority of important questions that fit within the bounds of linguistics as it is currently constituted have nothing to do with genetic influences!

Yet the significance of this finding is also fundamental, because it suggests that largescale patterns of language evolution, change and diversity are not somehow insulated from biology, culture, and the environment. Wong's work can be seen as part of a larger research program aiming to 're-root' language in its wider context through complex 'triangulations' using approaches from multiple fields (Dediu, Janssen, and Moisik 2017, Dediu and Moisik 2019, Blasi et al. 2019, Everett 2018, Everett, Blasi, and Roberts 2016, Lupyan and Dale 2016). Linguists cannot explore all this themselves; as we just noted, this finding depended crucially on interdisciplinary cooperation, and we are not suggesting that linguists should now all become experts in genetics, brain imaging, and advanced statistics. We do believe, though, that linguists, regardless of their specialist concerns, should embrace the idea that language is ultimately a biological phenomenon and may therefore vary from individual to individual or from community to community for reasons that at first seem to lie beyond the boundaries of our field.

\section{Acknowledgments}

We record our thanks, first, to Patrick Wong, for his unrelenting belief in our proposal (possibly even firmer than our own), and to his collaborators; but we also thank the various colleagues who, across the years, have discussed, supported, and commented 
(sometimes harshly) on the proposal that genes and linguistic diversity might be related.

\section{Funding}

DD was funded by an IDEXLYON (16-IDEX-0005) Fellowship grant (2018-2021), and indirectly by the LabEx ASLAN (ANR-10-LABX-0081) of the University of Lyon within the program Investissements d'Avenir (ANR-11-IDEX-0007) of the French National Research Agency (ANR).

\section{Author contributions}

Both authors contributed equally to this work.

\section{Ethics}

Not applicable.

\section{Conflict of interests}

The authors declare no conflict of interest.

\section{References}

Asaridou, S. S.; A. TAKaShima.; D. Dediu.; P. HagoorT.; and J. M. McQueEn. 2016. Repetition Suppression in the Left Inferior Frontal Gyrus Predicts Tone Learning Performance. Cerebral Cortex 26.2728-2742. doi:10.1093/cercor/bhv126.

BARBUJANI, GUIDO.; and VINCENZA COLONNA. 2010. Human genome diversity: frequently asked questions. Trends in Genetics 26.285-295. doi:10.1016/j.tig.2010.04.002.

BERGSTRÖM, ANDERS. 2018. Genomic insights into the human population history of Australia and New Guinea. University of Cambridge thesis. doi:10.17863/CAM.20837. https://www.repository.cam.ac.uk/handle/1810/273775. 
Bergström, Anders.; Nano Nagle.; Yuan Chen.; Shane McCarthy.; Martin O. Pollard.; QASim Ayub.; STEPHEN WILCOX.; et al. 2016. Deep Roots for Aboriginal Australian Y Chromosomes. Current Biology 26.809-813. doi:10.1016/j.cub.2016.01.028.

Blasi, Damián E.; Steven Moran.; Scott R. MoisiK.; Paul Widmer.; Dan Dediu.; and Balthasar Bickel. 2019. Human sound systems are shaped by post-Neolithic changes in bite configuration. Science 363.eaav3218. doi:10.1126/science.aav3218.

BoeckX, CEDric Arnaud.; and Antonio Benítez-Burraco. 2014. The shape of the human language-ready brain. Language Sciences 5.282. doi:10.3389/fpsyg.2014.00282.

Bowden, Rory.; TAmmie S. MacFie.; Simon Myers.; Garrett Hellenthal.; ERIC Nerrienet.; RonAld E. Bontrop.; Colin Freeman.; Peter Donnelly.; and Nicholas I. Mundy. 2012. Genomic Tools for Evolution and Conservation in the Chimpanzee: Pan troglodytes ellioti Is a Genetically Distinct Population. PLoS Genetics 8.e1002504. doi:10.1371/journal.pgen.1002504.

BRoSNAHAN, LEONARD FRANCIS. 1961. The Sounds of Language: An Inquiry into the Role of Genetic Factors in the Development of Sound Systems. Cambridge: W. Heffer and Sons.

Butcher, ANDREW. 2006. Australian aboriginal languages: Consonant-Salient Phonologies and the 'Place-of-Articulation Imperative.' Speech Production: Models, Phonetic Processes, and Techniques, ed. by John Harrington and Marija Tabain, 187-210. Macquarie Monographs in Cognitive Science. Psychology Press: NY. https://www.researchgate.net/publication/251509897_Australian_Aboriginal_languages_C onsonant_salient_phonologies_and_the_\%27place-of-articulation_imperative.

Caldwell-Harris, Catherine L.; Alia LanCaster.; D. Robert Ladd.; Dan Dediu.; and Morten H. ChristiAnSEn. 2015. Factors Influencing Sensitivity To Lexical Tone In An Artificial Language. Studies in Second Language Acquisition 37.335-357. doi:10.1017/S0272263114000849.

Darlington, Cyril Dean. 1947. The Genetic Component Of Language. Heredity 1.269-286. doi:10.1038/175178b0.

DEDIU, DAN. 2007. Non-spurious correlations between genetic and linguistic diversities in the context of human evolution. University of Edinburgh phd thesis. http://www.ling.ed.ac.uk/ simon/dissertations/DediuPhDThesis2007.pdf.

DEDIU, DAN. 2008. The role of genetic biases in shaping language-genes correlations. Journal of Theoretical Biology 254.400-407. doi:doi:10.1016/j.jtbi.2008.05.028.

DEDIU, DAN. 2009. Genetic biasing through cultural transmission: do simple Bayesian models of language evolution generalize? Journal of Theoretical Biology 259.552-561. doi:10.1016/j.jtbi.2009.04.004.

DEDIU, DAN. 2011. Are languages really independent from genes? If not, what would a genetic bias affecting language diversity look like? Hum Biol 83.279-296. doi:10.3378/027.083.0208. 
DEDIU, DAN.; RICK JANSSEN.; and SCOTT R. MoISIK. 2017. Language is not isolated from its wider environment: vocal tract influences on the evolution of speech and language. Language and Communication 54.9-20. doi:doi:10.1016/j.langcom.2016.10.002.

DEDIU, DAN.; and D. ROBERT LADD. 2007. Linguistic tone is related to the population frequency of the adaptive haplogroups of two brain size genes, ASPM and Microcephalin. Proc Natl Acad Sci U S A 104.10944-9. doi:10.1073/pnas.0610848104.

DEDIU, DAN.; and SCOTT R. MoISIK. 2019. Pushes and pulls from below: Anatomical variation, articulation and sound change. Glossa: a journal of general linguistics 4.7. doi:10.5334/gjgl.646.

Deriziotis, Pelagia.; and Simon E. Fisher. 2017. Speech and Language: Translating the Genome. Trends in Genetics 33.642-656. doi:10.1016/j.tig.2017.07.002.

Devanna, Paolo.; Dan Dediu.; and Sonja C. Vernes. 2018. The Genetics of Language: From complex genes to complex communication. The Oxford Handbook of Psycholinguistics, ed. by ShirleyAnn Rueschemeyer and M. Gareth Gaskell, 864-898. Oxford University Press. doi:10.1093/oxfordhb/9780198786825.013.37. http://oxfordhandbooks.com/view/10.1093/oxfordhb/9780198786825.001.0001/oxfordh b-9780198786825-e-37.

Dixon, Michael J.; Mary L. Marazita.; Terri H. Beaty.; and Jeffrey C. Murray. 2011. Cleft lip and palate: synthesizing genetic and environmental influences. Nature reviews. Genetics 12.167-178. doi:10.1038/nrg2933.

Evans, Patrick D.; SAndra L. GIlbert.; Nitzan Mekel-Bobrov.; Eric J. VAlLENDER.; JefFrey R. Anderson.; Leila M. VAez-AzizI.; SARAH A. TishKoff.; Richard R. Hudson.; and BRuCE T. LahN. 2005. Microcephalin, a gene regulating brain size, continues to evolve adaptively in humans. Science 309.1717-1720. doi:10.1126/science.1113722.

EVERETT, CALEB. 2018. The global dispreference for posterior voiced obstruents: A quantitative assessment of word-list data. Language 94.e311-e323. doi:10.1353/lan.2018.0069.

EveretT, CALEB.; DAmián E. Blasi.; and SEÁn G. RoBerTs. 2016. Language evolution and climate: the case of desiccation and tone. Journal of Language Evolution 1.33-46. doi:10.1093/jole/lzv004.

FISHER, SIMON E. 2019. Human Genetics: The Evolving Story of FOXP2. Current Biology 29.R65-R67. doi:10.1016/j.cub.2018.11.047.

Fisher, Simon E.; and Sonja C. Vernes. 2015. Genetics and the Language Sciences. Annual Review of Linguistics 1.289-310. doi:10.1146/annurev-linguist-030514-125024.

GoKhman, David.; MalKa Nissim-Rafinia.; Lily Agranat-Tamir.; Genevieve Housman.; Raquel GarcíaPÉREZ.; ESTHER LIZANO.; OLIVIA CHERONET.; et al. 2020. Differential DNA methylation of vocal and facial anatomy genes in modern humans. Nature Communications 11. Nature Publishing Group.1-21. doi:10.1038/s41467-020-15020-6. 
Jobling, Mark A.; EdWARd HolloX.; MatThew Hurles.; Toomas Kivisild.; and Chris Tyler-Smith. 2013. Human evolutionary genetics. New York: Garland Science.

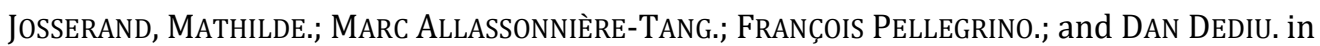
preparation. Interindividual variation refuses to go away: a Bayesian computer model of language change in communicative networks. Frontiers in Language Sciences.

Kirby, Simon.; Hannah CoRniSh.; and Kenny SMith. 2008. Cumulative cultural evolution in the laboratory: An experimental approach to the origins of structure in human language. Proceedings of the National Academy of Sciences 105.10681-10686. doi:10.1073/pnas.0707835105.

KIRBY, Simon.; Mike Dowman.; and Thomas L. GrifFiTHS. 2007. Innateness and culture in the evolution of language. Proc Natl Acad Sci U S A 104.5241-5. doi:10.1073/pnas.0608222104.

LADD, D. RoberT.; DAN DEDIU.; and ANNA R. KinSELLA. 2008. Languages and Genes: Reflections on Biolinguistics and the Nature-Nurture Question. Biolinguistics 2.114-126.

LADD, D. Robert.; SeÁn G. RoBerTS.; and DAN Dediu. 2015. Correlational Studies in Typological and Historical Linguistics. Annual Review of Linguistics 1.221-241. doi:10.1146/annurev-linguist030514-124819.

Ladd, D. Robert.; R. Turnbull.; C. Browne.; C. Caldwell-HaRRIs.; L.Y. GanushChaK.; K. Swoboda.; V. WoodfieLD.; and D. DEDIU. 2013. Patterns of individual differences in the perception of missing-fundamental tones. Journal of Experimental Psychology: Human Perception and Performance 39.1386-1397. doi:10.1037/a0031261.

LADEFoged, Peter. 1984. 'Out of Chaos Comes Order'; Physical, biological, and structural patterns in phonetics. Proceedings of the Tenth International Congress of Phonetic Sciences, ed. by Cohen A. and Van den Broecke, M.P.R., IIB:83-95. Foris Publications: Dordrecht, Holland. file://home/deddan/Work/References/Papers/Out of Chaos Comes Order - Ladefoged.pdf. LEVINSON, STEPHEN C.; and DAN DEDIU. 2013. The interplay of genetic and cultural factors in ongoing language evolution. Cultural evolution: Society, technology, language, and religion, ed. by Richerson, P.J. and Christiansen, M.H., 12:219-232. Strüngmann Forum Reports. Cambridge, Mass: MIT Press.

LEWONTIN, RICHARD C. 1972. The apportionment of human diversity. Evolutionary biology, ed. by Theodosius Dobzhansky, Max K. Hecht, and William C. Steere, 6:381-398. Springer, New York. https://link.springer.com/chapter/10.1007/978-1-4684-9063-3_14.

LUPYAN, GARY.; and Rick DALE. 2016. Why Are There Different Languages? The Role of Adaptation in Linguistic Diversity. Trends in Cognitive Sciences 20.649-660. doi:10.1016/j.tics.2016.07.005.

MacDermot, Kay D.; Elena Bonora.; Nuala Sykes.; AnNe-Marie Coupe.; Cecilia S. L. Lal.; Sonja C. VERNES.; FARANEH VARGHA-KHADEM.; et al. 2005. Identification of FOXP2 Truncation as a Novel 
Cause of Developmental Speech and Language Deficits. American Journal of Human Genetics 76.1074-1080.

McEvoy, Brian P.; JoAnne M. Lind.; ERIC T. WAng.; Robert K. Moyzis.; Peter M. Visscher.; Sheila M. van Holst PellekaAn.; and Alan N. Wilton. 2010. Whole-Genome Genetic Diversity in a Sample of Australians with Deep Aboriginal Ancestry. American Journal of Human Genetics 87.297-305. doi:10.1016/j.ajhg.2010.07.008.

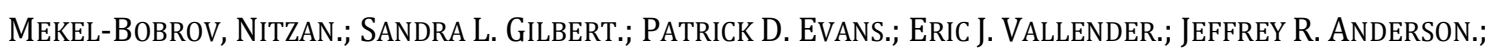
RichARD R. HUdSON.; SARAH A. TISHKOFF.; and BRUCE T. LAHN. 2005. Ongoing adaptive evolution of ASPM, a brain size determinant in Homo sapiens. Science 309.1720-1722. doi:10.1126/science.1116815.

Nassir, Rami.; Roman Kosoy.; Chao Tian.; Phoebe A. White.; Lesley M. Butler.; Gabriel Silva.; Rick KITTLES.; et al. 2009. An ancestry informative marker set for determining continental origin: validation and extension using human genome diversity panels. BMC Genetics 10.39 . doi:10.1186/1471-2156-10-39.

Navarro, Danielle J.; Amy Perfors.; Arthur Kary.; Scott D. Brown.; and Chris Donkin. 2018. When Extremists Win: Cultural Transmission Via Iterated Learning When Populations Are Heterogeneous. Cognitive Science 42.2108-2149. doi:10.1111/cogs.12667.

Paschou, Peristera.; Jamey LeWis.; Asif JaVed.; and Petros Drineas. 2010. Ancestry informative markers for fine-scale individual assignment to worldwide populations. Journal of Medical Genetics 47.835-847. doi:10.1136/jmg.2010.078212.

Passemard, Sandrine.; Alain Verloes.; Thierry Billette de Villemeur.; Odile BoespFlug-Tanguy.; Karen HERNANDEZ.; MARION LAURENT.; BERTRAND ISIDOR.; et al. 2016. Abnormal spindle-like microcephaly-associated (ASPM) mutations strongly disrupt neocortical structure but spare the hippocampus and long-term memory. Cortex; a Journal Devoted to the Study of the Nervous System and Behavior 74.158-176. doi:10.1016/j.cortex.2015.10.010.

PERforS, AMY.; and DANIEL NAVARRO. 2011. Language evolution is shaped by the structure of the world: An iterated learning analysis. Proceedings of the 33rd Annual Conference of the Cognitive Science Society, Austin, TX. Cognitive Science Society. http://csjarchive.cogsci.rpi.edu/Proceedings/2011/papers/0089/paper0089.pdf.

Pugach, Irina.; Frederick Delfin.; ElLEN GunNARSDótTiR.; MANFREd KAYSER.; and MARK STONEKING. 2013. Genome-wide data substantiate Holocene gene flow from India to Australia. Proceedings of the National Academy of Sciences. doi:10.1073/pnas.1211927110. http://www.pnas.org/content/early/2013/01/09/1211927110.

RAVIV, LIMOR. 2020. Language and society: How social pressures shape grammatical structure. Nijmegen, The Netherlands: Radboud University/Mac Planck Institute for Psycholinguistics phd thesis. 
REICH, DAVID. 2018. Who We Are and How We Got Here: Ancient DNA and the new science of the human past. Oxford, UK: Oxford University Press.

RoUND, ERICH R. 2019. Stable instability: How recurrent lenition across Australian languages reinforces existing phonological systems. SLE 2019Book of Abstracts, ed. by Olga Spevak, 584-586. Leipzig University, Germany: Societas Linguistica Europaea. http://sle2019.eu/downloads/SLE\%202019\%20BOOK\%200F\%20ABSTRACTS.pdf.

SMith, KenNy. 2009. Iterated learning in populations of Bayesian agents. Proceedings of the 31st Annual Conference of the Cognitive Science Society, 697-702. http://141.14.165.6/CogSci09/papers/123/paper123.pdf.

SMith, KENNY.; and ElizABETH WonNACOTT. 2010. Eliminating unpredictable variation through iterated learning. Cognition 116.444-449. doi:10.1016/j.cognition.2010.06.004.

Thompson, BILL.; Simon KirBY.; and KenNy Smith. 2016. Culture shapes the evolution of cognition. Proceedings of the National Academy of Sciences 113.4530-4535. doi:10.1073/pnas.1523631113.

Wong, Patrick C M.; Bharath Chandrasekaran.; and Jing Zheng. 2012. The Derived Allele of ASPM Is Associated with Lexical Tone Perception. PLoS One 7.e34243. doi:10.1371/journal.pone.0034243.

Wong, Patrick C. M.; Xin Kang.; Kay H. Y. Wong.; Hon-Cheong So.; Kwong Wai ChoY.; and Xiujuan Geng. 2020. ASPM-lexical tone association in speakers of a tone language: Direct evidence for the genetic-biasing hypothesis of language evolution. Science Advances 6. American Association for the Advancement of Science.eaba5090. doi:10.1126/sciadv.aba5090. 


\section{Appendix}

This Appendix provides additional detail about:

(1) the original papers that reported on the uneven geographical distribution of the derived alleles of $A S P M$ and MCPH1 (Mekel-Bobrov et al. 2005, Evans et al. 2005);

(2) the original correlational study of $A S P M, M C P H 1$, and linguistic tone (Dediu and Ladd 2007 and various follow-up studies);

(3) the first experimental paper investigating behavioural differences related to linguistic tone in individuals genotyped for ASPM and MCPH1 (Wong, Chandrasekaran, and Zheng 2012).

\section{The original ASPM and MCPH1 papers}

The original aim of the two papers introducing the 'derived' alleles of ASPM (MekelBobrov et al. 2005) and MCPH1 of Microcephalin (Evans et al. 2005) was twofold. First, they documented the uneven geographical distribution of the derived alleles on the basis of a survey of 59 populations, most of which, however, were from the Old World (only 5 from the Americas). Second, they provided evidence for the relatively recent evolution of the derived alleles and for the hypothesis that in both cases the derived alleles seem to have been favored by selective pressure, possibly related to 'intelligence': MCPH1-D was said to have originated approximately 37,000 years ago and $A S P M$-D 6800 years ago.

The original claims of two papers have not all been supported by subsequent research: there is agreement now that the method used to identify the claimed positive selection is not reliable (Currat et al. 2006; Timpson et al. 2007), and, more importantly, that there is no link to 'intelligence' (Mekel-Bobrov et al. 2007; Rushton, Vernon, and Bons 2007; Saini 2019) despite claims to contrary (Woodley et al. 2014). However, these two genes do seem to have played crucial roles in the evolution of the brain (Ali and Meier 2008; Montgomery and Mundy 2012; Cox et al. 2006; 
Montgomery and Mundy 2010), and, as we discuss later, the 'derived' allele of ASPM does seem to be involved in normal inter-individual variation.

Further information about the 'derived' alleles of ASPM and MCPH1 can be found under several 'names' in different publications and databases.

- For ASPM, the original publication (Mekel-Bobrov et al. 2005) defines the ' $\mathrm{D}$ ' ('derived') and 'non-D' ('ancestral') alleles with reference to 'haplotype 63' and two of its polymorphic nonsynonymous sites in exon 18, $A 44871 G$ and C45126A, with the ancestral alleles, respectively, $A$ and $C$, and the derived ones, G and A; more recent publications use SNP rs41310927 with ancestral allele T and derived allele $\mathrm{C}$.

- For MCPH1 (or Microcephalin), these were originally defined (Evans et al. 2005 ) in relation to $G 37995 C$ in exon 8, with the ancestral allele, and the derived one C; more recent publications use SNP $\underline{\text { rs } 930557}$ with ancestral allele $\mathrm{G}$ and derived allele $\mathrm{C}$.

\section{Dediu \& Ladd (2007): summary of methods and results}

Our original study included only 49 of the 59 populations in the original Science papers (Mekel-Bobrov et al. 2007, Evans et al. 2005). We deliberately focused only on Old World populations, as the sampling of American groups was far too sparse to support any conclusions. We also omitted a few of the Old World populations, mostly because of insufficient genetic and linguistic data. Genetic information was taken primarily from Mekel-Bobrov et al. (2005) and Evans et al. (2005), but was supplemented from other databases such as ALFRED (Rajeevan 2003) and HGDP (Cavalli-Sforza 2005). Linguistic classification was based primarily on WALS (Haspelmath et al. 2005), supplemented by direct contact with specialists in the various languages (see Dediu and Ladd 2007:10947 for details). With these data, we estimated the statistical association of tone with the population frequency of $A S P M-D$ (the 'D' allele of $A S P M$ ) and MCHP1-D, both individually (Pearson's $r$ ) and together (logistic regression), and we compared these estimates with those of all the other 
possible associations of all linguistic features and all (pairs of) genetic markers in our database.

The most important problem for any such study is to control for possible confounds that might explain any correlation. For example, given that both language and genes are transmitted across generations, they show 'genealogic inertia', which means that related languages (and populations) are more similar that they should be simply because they inherit, through common descent, from the same ancestral language (population); this confound is known as 'Galton's problem' in comparative studies (Mace and Pagel 1994, Ladd, Roberts, and Dediu 2015). Another source of confounding is contact (linguistic borrowing and genetic admixture/inter-breeding), which means that languages (and populations) in contact are more similar than they should be due to vertical transmission only. Both of these sources of statistical nonindependence have the potential to distort ordinary statistical inference, and to inflate the significance of tests of association (such as the ones we used), increasing thus the probability of false positives.

While there are now various recommended techniques for managing these sources of non-independence (including phylogenetics and mixed-effects models; see Ladd, Roberts, and Dediu, 2015, Jaeger et al., 2011, Roberts and Winters, 2013 for more), we used Mantel correlations (Mantel 1967), which estimate the association between two distance matrices while controlling for other distance matrices, and dealing with the non-independence of the distances by repeatedly permuting the data. In our case, the two distance matrices are, first, the structural distance between the languages (the Euclidean distance on the space defined by one or more structural features), which captures the structural similarity between languages, and second, the genetic distance between populations (using the standard Nei's D; Nei 1972), which captures the similarity of allele frequency between them. As controls, we used the geographic distance between languages (constrained by the geography of the world), to capture the idea that languages closer in space may be in more intense contact, and a historical linguistic distance (computed using the language family classifications in 
the $15^{\text {th }}$ edition of the Ethnologue; Gordon 2005), which quantifies their degree of closeness in genealogical terms. The partial Mantel correlation between the two genes and tone, after controlling for geographical and genealogical distance, is significant, suggesting that there is something about tone, ASPM-D and MCPH1-D that is not due to shared ancestry and contact.

Beyond possible enlargements of the dataset and the adoption of more recently developed statistical techniques, since the appearance of Dediu and Ladd (2007) other studies have adopted other 'large-scale' approaches that exploit the observed patterns of linguistic diversity in the search for further evidence of crosslinguistic/cross-population associations between tone and the two genes. For example, if the presence or absence of linguistic tone is affected by the genetic makeup of the population of speakers, then, given that gene frequencies usually (though not always; Pagel, Atkinson, and Meade 2007) change more slowly than language structures, then we would predict that linguistic tone should be among the most stable features of language. Indeed, this seems to be borne out by phylogenetic (Dediu 2011) and various non-phylogenetic (Dediu and Cysouw 2013; Kauhanen et al. 2018) methods that try to infer the genealogical (and/or areal) stability of structural properties of language from large cross-linguistic databases (see Dediu and Cysouw 2013 for discussion). However, there are other features that are most stable than tone, and in any case such stability can be due to many other factors besides genes (Dediu and Cysouw 2013; Nichols 2008).

\section{Summary of Wong, Chandrasekaran and Zheng (2012)}

Like the more recent 2020 study that is the focus of the main text, Wong, Chandrasekaran, and Zheng (2012) relied on classifying their experimental participants according to their 'load' of the genes of interest. Recall that humans normally have two copies of the same locus for most of their genes, one copy inherited from the mother and one from the father. This means that each individual will have 
two copies of, for example, $A S P M$, which may or may not be the allele of interest. Specifically, an individual can have two copies of the ancient or non-derived allele (a $\left\{\right.$ 'non-D','non-D'\} genotype), two copies of the derived allele $\left(\left\{D^{\prime}, D^{\prime}\right\}\right)$, or one copy of each $\left(\left\{{ }^{\prime} D^{\prime}\right.\right.$, 'non- $\left.\left.D '\right\}\right)$. The 'load' of the allele of interest is therefore 0,1 , or 2 .

In the Wong, Chandrasekaran, and Zheng (2012) study, for ASPM there were 14 \{'nonD','non-D'\}, 12 \{'D','non-D'\} and 6 \{'D','D'\} participants; for MCPH1 there were 10 $\left\{{ }^{\prime} D^{\prime}, '\right.$ non-D'\} and $22\left\{{ }^{\prime} D^{\prime}, D^{\prime}\right\}$, but no \{'non-D','non-D'\} participants (which is not surprising, given the population frequency of the ' $\mathrm{D}$ ' allele in Europe; Evans et al. 2005). The participants in this study are defined as adult native speakers of American English, all self-identified 'Caucasians'. Obviously, 'racial' classifications in the US are highly problematic and probably reflect much more (and less) than actual ancestry (Saini 2019, Roberts 2011), but, for this particular study, they may fulfil their intended function, namely to reduce the undue confounding effects of population structure. Each participant was genotyped for the presence or absence of the ' $\mathrm{D}$ ' allele at each of the loci, and the load of the derived allele ' $\mathrm{D}$ ' at each locus was computed as the number of 'D' alleles at the locus (i.e., a participant with alleles \{'D', 'non-D'\} for $A S P M$ and \{'D','D'\} for MCPH1 would have load 1 for ASPM and load 2 for MCPH1).

All the participants performed various control tasks (auditory working memory and phonemic awareness), but also a tone perception task where they listened to a set of resynthesized Mandarin vowels (/a i o e y/) with Mandarin tones superimposed (tone 1 level, tone 2 rising, tone 4 falling), and for which they had to pick the correct direction of the pitch (represented by the arrows $\rightarrow$, $\uparrow$, and $\downarrow$, respectively) from among two such arrows shown on the screen (one correct and one distractor). A subset of 13 participants also participated in an fMRI adaptation experiment and did a test of non-verbal intelligence. The fMRI experiment involving listening to series of Mandarin vowels with any of the four Mandarin tones and looked for evidence of 'repetition suppression' - a phenomenon in which a participant's BOLD response (Blood-Oxygen-Level-Dependent, reflecting blood flow that brings oxygen to the 
active areas of the brain) 'adapts' to the repeated presentation of the same stimulus, in this case the same Mandarin tone. The ostensible task during the fMRI study required participants to pay attention to changes in loudness, not pitch. While it is unclear what such 'repetition suppression' exactly means, it seems to reflect at least the fact that the brain detects the stimulus and adapts its processing strategy (Asaridou et al. 2016, Wong, Chandrasekaran, and Zheng 2012).

The idea of the study as a whole was to see if the derived-allele load in ASPM and MCHP1 helped predict the participants' performance in the behavioural toneidentification task and/or in the fMRI adaptation procedure, after controlling for potential confounds (such as age, sex, and working memory). As discussed in the main text, the study did find effects related to $A S P M$, but not to $M C P H 1$, though the effects of $A S P M$ appeared to be the opposite of what was predicted by Dediu and Ladd.

\section{Supplementary references}

Ali, FARHAN.; and RUdolf MEIER. 2008. Positive selection in ASPM is correlated with cerebral cortex evolution across primates but not with whole-brain size. Mol Biol Evol 25.2247-2250. doi:10.1093/molbev/msn184.

ASARIdou, S. S.; A. TAKAShimA.; D. DediU.; P. HAGoorT.; and J. M. McQueEN. 2016. Repetition Suppression in the Left Inferior Frontal Gyrus Predicts Tone Learning Performance. Cerebral Cortex 26.2728-2742. doi:10.1093/cercor/bhv126.

CAVAlli-SforzA, L. LuCA. 2005. The Human Genome Diversity Project: past, present and future. Nature Reviews Genetics 6.333-340. doi:10.1038/nrg1596.

COX, JAMES.; ANDREW P. JACKSON.; JACQUELYN BOND.; and CHRISTOPHER G. WOODS. 2006. What primary microcephaly can tell us about brain growth. Trends Mol Med 12.358-366. doi:10.1016/j.molmed.2006.06.006.

Currat, Mathias.; Laurent Excoffier.; Wayne Maddison.; SARAH P. OtTo.; Nicolas Ray.; Michael C. WHITLOCK.; and SAM YEAMAN. 2006. Comment on 'Ongoing adaptive evolution of ASPM, a brain size determinant in Homo sapiens' and 'Microcephalin, a gene regulating brain size, continues to evolve adaptively in humans.' Science (New York, N.Y.) 313.172; author reply 172. doi:10.1126/science.1122712.

DEDIU, DAN. 2011. A Bayesian phylogenetic approach to estimating the stability of linguistic features and the genetic biasing of tone. Proc R Soc B 278.474-479. doi:10.1098/rspb.2010.1595. 
Dediu, DAn.; and Michael Cysouw. 2013. Some Structural Aspects of Language Are More Stable than Others: A Comparison of Seven Methods. PLoS ONE 8.e55009. doi:10.1371/journal.pone.0055009.

DEDIU, DAN.; and D. ROBERT LADD. 2007. Linguistic tone is related to the population frequency of the adaptive haplogroups of two brain size genes, ASPM and Microcephalin. Proc Natl Acad Sci U S A 104.10944-9. doi:10.1073/pnas.0610848104.

Evans, Patrick D.; Sandra L. GIlbert.; NitZan MEKel-Bobrov.; Eric J. VAlLENDER.; JefFrey R. Anderson.; LEILA M. VAEZ-AZIZI.; SARAH A. TishKoff.; Richard R. Hudson.; and BruCE T. Lahn. 2005. Microcephalin, a gene regulating brain size, continues to evolve adaptively in humans. Science 309.1717-1720. doi:10.1126/science.1113722.

GORDON, R. G. (ed.) 2005. Ethnologue: Languages of the World. 15th ed. SIL International. http://www.ethnologue.com/.

Haspelmath, Martin, MatThew S. Dryer, David GiL, and Bernard Comrie (eds.) 2005. The World Atlas of Language Structures. Oxford University Press.

Jaeger, T. Florian.; Peter GrafF.; William Croft.; and Daniel Pontillo. 2011. Mixed effect models for genetic and areal dependencies in linguistic typology. Linguistic Typology 15.281-319. doi:10.1515/lity.2011.021.

Kauhanen, Henri.; DeEPThi Gopal.; Tobias Galla.; and Ricardo BermúdeZ-OTero. 2018. Geospatial distributions reflect rates of evolution of features of language. arXiv:1801.09637 [cond-mat, physics:nlin, physics:physics]. http://arxiv.org/abs/1801.09637.

Ladd, D. Robert.; SeÁn G. RoberTS.; and DAn Dediu. 2015. Correlational Studies in Typological and Historical Linguistics. Annual Review of Linguistics 1.221-241. doi:10.1146/annurev-linguist030514-124819.

MaCE, Ruth.; and MaRK PAGel. 1994. The comparative method in anthropology. Current Anthropology 35.549-564.

MANTEL, N. 1967. The detection of disease clustering and a generalized regression approach. Cancer Res 27.209-20.

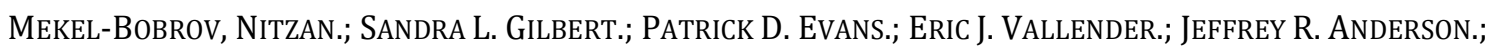
RiCHARD R. HUdSON.; SARAH A. TISHKOFF.; and BRUCE T. LAHN. 2005. Ongoing adaptive evolution of ASPM, a brain size determinant in Homo sapiens. Science 309.1720-1722. doi:10.1126/science.1116815.

Mekel-Bobrov, Nitzan.; Danielle Posthuma.; Sandra L Gilbert.; Penelope Lind.; M Florencia Gosso.; MiChELLE LUCIANO.; E HARRIS, SARAH.; et al. 2007. The ongoing adaptive evolution of ASPM and Microcephalin is not explained by increased intelligence. Hum Mol Genet 16.600-8.

MONTGOMERY, STEPHEN H.; and NiCHOLAS I MUNDY. 2010. Brain evolution: microcephaly genes weigh in. Current biology: CB 20.R244-246. doi:10.1016/j.cub.2010.01.043. 
MONTGOMERY, STEPHEN H.; and NichOlAS I MunDY. 2012. Evolution of ASPM is associated with both increases and decreases in brain size in primates. Evolution; international journal of organic evolution 66.927-932. doi:10.1111/j.1558-5646.2011.01487.x.

NEI, M. 1972. Genetic Distance between Populations. The American Naturalist 106.283-292.

Nichols, Johanna. 2008. Diversity and Stability in Language. The Handbook of Historical Linguistics, ed. by Brian D. Joseph and Richard D. Janda, 283-310. Blackwell Publishing Ltd. http://onlinelibrary.wiley.com/doi/10.1002/9780470756393.ch5/summary.

PAGEL, MARK.; QUENTIN D. ATKInSON.; and ANDREW MEADE. 2007. Frequency of word-use predicts rates of lexical evolution throughout Indo-European history. Nature 449.717-721. doi:10.1038/nature06176.

RajEEVAN, H. 2003. ALFRED: the ALelle FREquency Database. Update. Nucleic Acids Research 31.270271. doi:10.1093/nar/gkg043.

RoBerts, DoRothy E. 2011. Fatal Invention: How Science, Politics, and Big Business Re-create Race in the Twenty-first Century. New Press.

ROBERTS, SEÁn.; and JAMES WinTERS. 2013. Linguistic Diversity and Traffic Accidents: Lessons from Statistical Studies of Cultural Traits. PLoS ONE 8.e70902. doi:10.1371/journal.pone.0070902.

Rushton, J. PhilipPe; Philip A. Vernon.; and Trudy Ann Bons. 2007. No evidence that polymorphisms of brain regulator genes Microcephalin and ASPM are associated with general mental ability, head circumference or altruism. Biol Lett 3.157-160. doi:10.1098/rsbl.2006.0586.

SAINI, ANGELA. 2019. Superior: The Return of Race Science. HarperCollins UK.

Timpson, Nicholas.; Jon Heron.; George Davey Smith.; and WolfGang Enard. 2007. Comment on papers by Evans et al. and Mekel-Bobrov et al. on Evidence for Positive Selection of MCPH1 and ASPM. Science (New York, N.Y.) 317.1036; author reply 1036. doi:10.1126/science.1141705.

Wong, Patrick C M.; Bharath ChandRasekaran.; and Jing Zheng. 2012. The Derived Allele of ASPM Is Associated with Lexical Tone Perception. PLoS One 7.e34243. doi:10.1371/journal.pone.0034243.

Woodley, Michael A.; Heiner Rindermann.; EdWARD Bell.; JAmes STRATford.; and DAVIDE Piffer. 2014. The relationship between Microcephalin, ASPM and intelligence: A reconsideration. Intelligence 44.51-63. doi:10.1016/j.intell.2014.02.011. 